УДК 58.01/.07, 581.143, 612.017.2

\title{
ИСПОЛЬЗОВАНИЕ ШТАММОВ PSEUDОМОNAS MIGULA ПРИ АДАПТАЦИИ К НЕСТЕРИЛЬНЫМ УСЛОВИЯМ PACTЕНИЙ RUBUS OCCIDENTALIS CUMBERLAND, ПОЛУЧЕННЫХ МЕТОДОМ IN VITRO
}

Тохтарь Людмила Анатольевна к.б.н., зав. лабораторией биотехнологии растений Третьяков Михаил Юрьевич к.б.н., зав. лабораторией генетики и селекции растений

Жиляева Наталья Васильевна инженер лаборатории биотехнологии растений НОЦ «Ботанический сад НИУ «БелГУ»

Аннотация: В статье приводятся данные по влиянию некоторых штаммов Pseudomonas Migula на адаптацию растений Rubus occidentalis Cumberland, полученных методом in vitro, к условиям внешней среды. Выявлено положительное влияние обработки торфяного субстрата перед высадкой растений малины на адаптацию суспензией, содержащей штаммы бактерий Pseudomonas в разведении 1:5 на длину корней и высоту растений. Среди изученных штаммов штамм Pseudomonas putida P82 в разведении 1:5 и Pseudomonas protegens P4-2 в разведении 1:10 выступают в качестве ингибиторов образования количества междоузлий и длины корней.

Ключевые слова: Адаптация, in vitro, Rubus occidentalis Cumberland., штаммы Pseudomonas Migula.

\section{USE OF PSEUDOMONAS MIGULA STRAINS WHEN ADAPTING TO NON-STERILE CONDITIONS RUBUS OCCIDENTALIS CUMBERLAND PLANTS, OBTAINED BY IN VITRO METHOD}

Tokhtar Lyudmila Anatolyevna Tretyakov Mikhail Yurievich Zhilyaeva Natalia Vasilievna 
Abstract: The article provides data on the effect of some Pseudomonas Migula strains on the adaptation of Rubus occidentalis Cumberland plants obtained by the in vitro method to environmental conditions. The positive effect of peat substrate treatment before planting raspberry plants on adaptation with a suspension containing Pseudomonas bacteria strains at a dilution of 1: 5 on root length and plant height was revealed. Among the strains studied, the Pseudomonas putida P82 strain at a 1: 5 dilution and Pseudomonas protegens P4-2 at a 1:10 dilution act as inhibitors of the formation of the number of internodes and root length.

Key words: adaptation, in vitro, Rubus occidentalis Cumberland, Pseudomonas strains.

Для быстрого размножения различных видов растений широкое применение в практике питомниководства нашел метод клонального микроразмножения. Этот метод стал промышленным для многих культур, в том числе и для малины [1].

Эффективность клонального микроразмножения растений рода Rubus $\mathrm{L}$. во многом зависит от генотипических факторов, влияние которых проявляется в способности к росту меристем, размножению и укоренению $[2,3]$. По мнению большинства исследователей, одним из наиболее трудоемких и уязвимых этапов клонального микроразмножения является адаптация регенерантов к нестерильным условиям: гибель пробирочных растений может быть весьма существенной и достигать $50 \%$ и более $[4,5]$. Высокая чувствительность микрорастений к стрессам и большие потери при адаптации заставляют искать пути увеличения их приживаемости в стрессовых условиях $[7,8]$ и активизации ростовых процессов на ранних этапах доращивания, именно поэтому успешный перенос растений в нестерильные условия делает возможным промышленное микроклональное размножение [9, 10, 11].

В опытах ряда исследователей было показано, что внесение комплексных микробных препаратов позитивно влияет на физиологическое состояние и метаболизм растений и обеспечивает снижение стрессовой нагрузки на регенеранты в период адаптации [12]. Это в свою очередь позитивно сказывается на процессах роста, интенсивности укоренения и проценте выхода стандартных саженцев. Бактерии Pseudomonas chlororaphis согласно литературным данным известны благодаря ингибированию развития 
фитопатогенных грибов [13]. Pseudomonas protegens рассматриваются в качестве бактерий, продуцирующих биологические активные вещества, тормозящие развитие патогенной микрофлоры [14]. Pseudomonas putida в литературе рассматривается в качестве микроорганизма симбионта синтезирующего предшественники гормонов растений, тем самым способствуя мобилизации питательных веществ и продуцирующего антибиотики [15]. Таким образом, применение препаратов, содержащих штаммы бактерий рода Pseudomonas Migula, могут облегчить переход регенерантов Rubus occidentalis Cumberland к самостоятельному минеральному питанию и фотосинтезу в асептических условиях, сократить потери микрорастений и вместе с тем ускорить их рост после пересадки ex vitro.

Целью настоящего исследования было изучить влияние подготовки субстрата с использованием суспензий, содержащих различные штаммы бактерий Pseudomonas Migula. - Pseudomonas chlororaphis 16H, Pseudomonas protegens P4-2 и Pseudomonas putida P82, на ростовые процессы in vitro растений Rubus occidentalis Cumberland на этапе адаптации.

Для адаптации к нестерильным условиям укорененные in vitro растения малины высаживались в рассадные кассеты с объемом ячейки 50 мл, заполненные минерализованным торфяным субстратом. Перед высадкой растений, субстрат в рассадных кассетах проливали до полного смачивания растворами, содержащими штаммы бактерий Pseudomonas chlororaphis $16 \mathrm{H}$, Pseudomonas protegens $\mathrm{P} 4-2$ и Pseudomonas putida $\mathrm{P} 82$ в разведениях с водой 1:5 и 1:10. В качестве контроля выступали растения, обработанные после высадки в субстрат водой без добавок. Кассеты с высаженными растениями размещались в парниках. В течение 30 дней влажность в парниках плавно снижали. После завершения процесса адаптации проводили оценку некоторых морфометрических параметров растений.

Полученные данные по влиянию обработки субстратов различными штаммами Pseudomonas Migula на морфометрические показатели надземной и подземной частей растений Rubus occidentalis Cumberland представлены на рисунках $1,2$. 


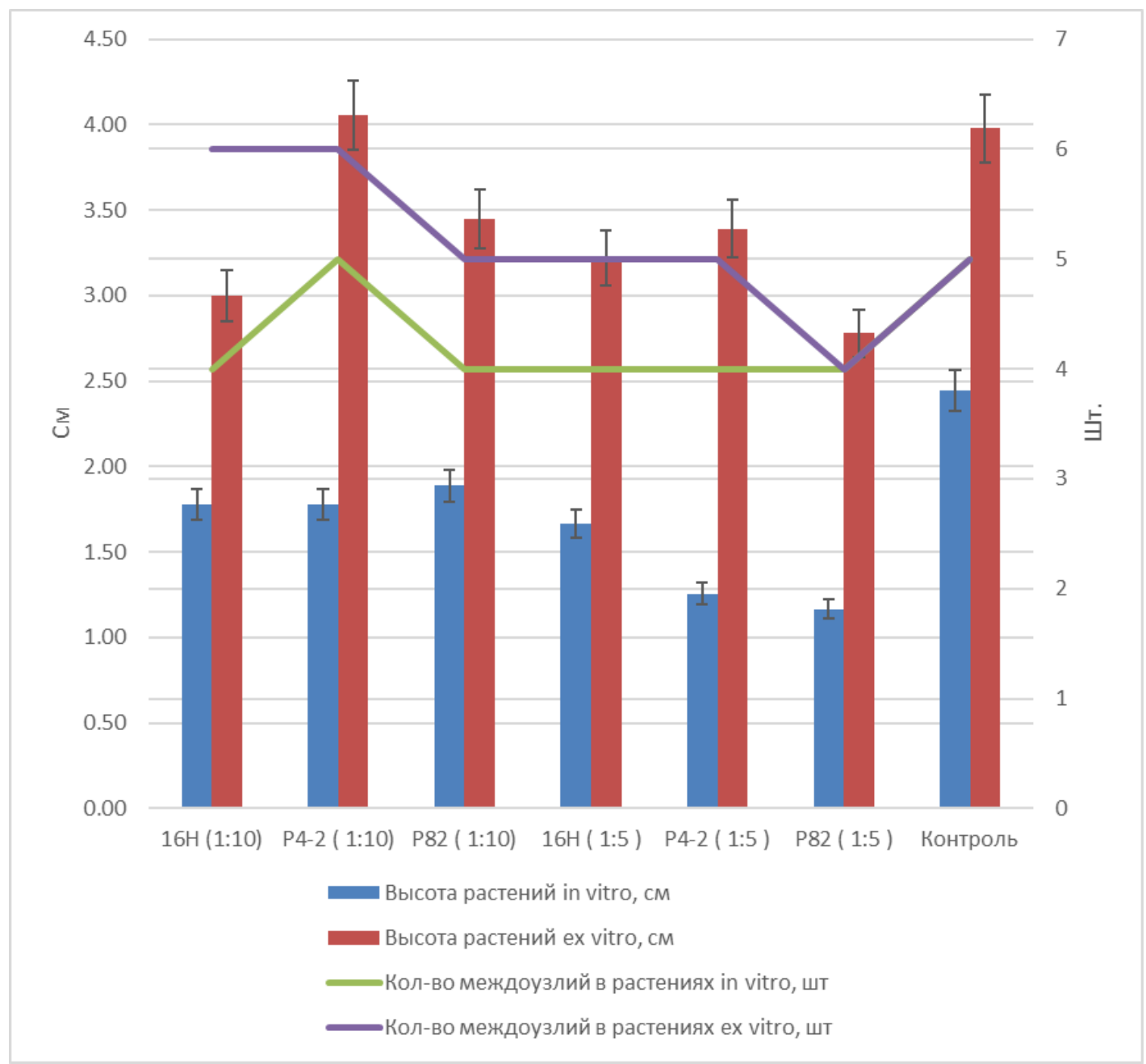

\section{Рис. 1. Влияние обработки субстрата штаммами Pseudomonas Migula на морфометрические показатели надземной части растений Rubus occidentalis Cumberland при адаптации к условиям ex vitro}

Растения, полученные методом in vitro, до адаптации имели разное количество междоузлий и отличались по средним значениям высоты растений. После завершения адаптации у растений, высаженных в субстрат обработанный суспензией содержащей изученные штаммы Pseudomonas Migula, количество междоузлий оказалось выше, чем у контрольных растений во всех вариантах, за исключением обработки субстрата Pseudomonas putida P82 в разведении 1:5. Несмотря на неравномерность длинны побегов малины в начале эксперимента можно с уверенностью констатировать, что процент приростов при использовании всех изученных штаммов Pseudomonas Migula и при всех разведениях был выше чем в контроле, где прирост составил $62,7 \%$, а при использовании обработки штаммами минимальный прирост составил $68,75 \%$ 
при использовании штамма Pseudomonas chlororaphis $16 \mathrm{H}$ и разведении 1:10 и максимальный прирост 169,9\% при использовании штамма Pseudomonas protegens P4-2 в разведении 1:5. Использование при обработки субстратов изученных штаммов Pseudomonas в разведение культур к 1:5 давало большие приросты, по сравнению с разведением 1:10.

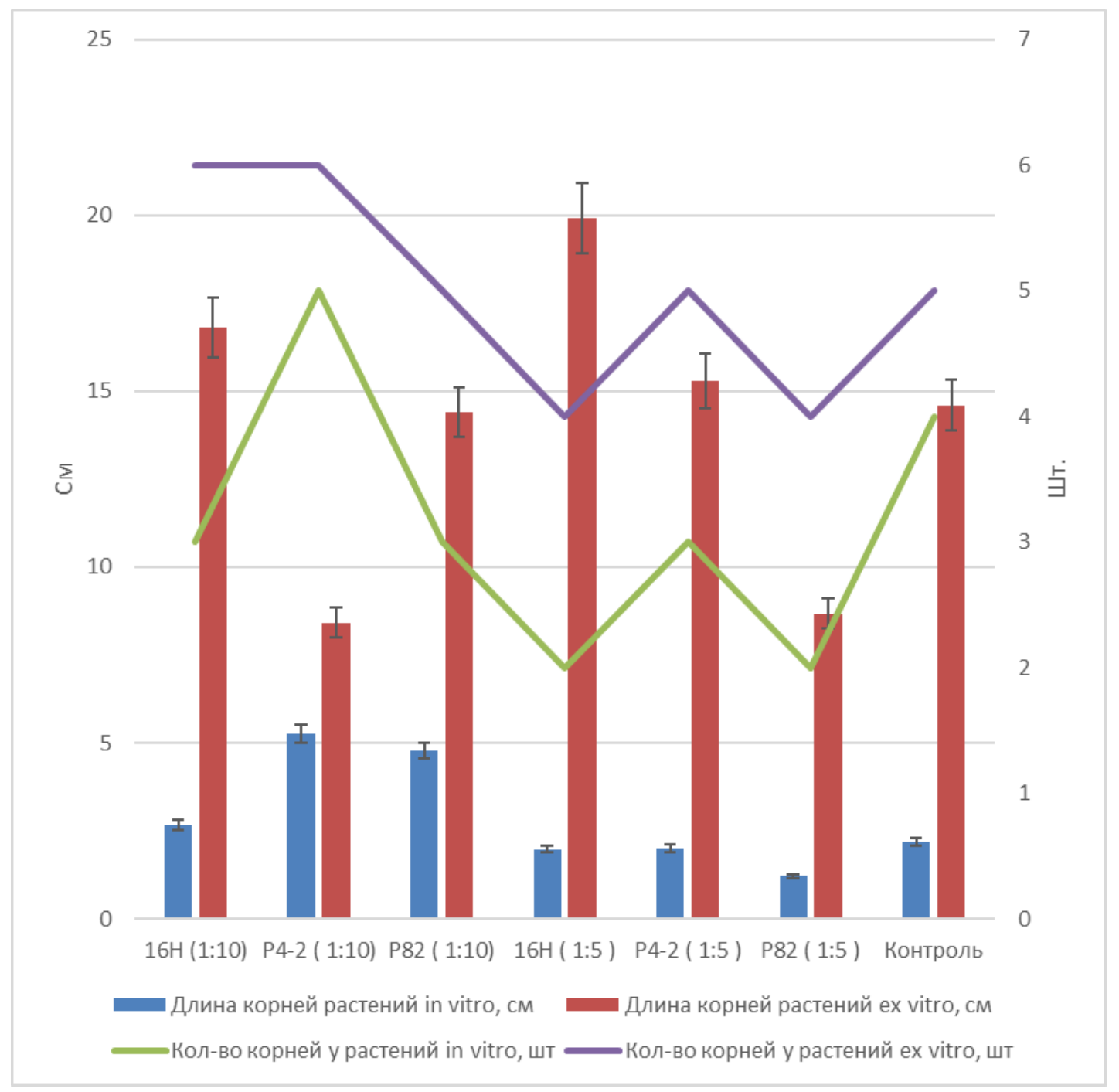

Рис. 2. Влияние обработки субстрата штаммами Pseudomonas Migula на развитие корневой системы растений Rubus occidentalis Cumberland при адаптации к условиям ex vitro

На рисунке 2 видно, что количество корней увеличивается при обработки всеми штаммами Pseudomonas, за исключением Pseudomonas protegens P4-2. Обработка субстратов также приводит и к увеличению длины корней Rubus occidentalis Cumberland в разведении 1:5 по сравнению с контролем, а в разведении 1:10 со всеми штаммами длина корней оказалась ниже, чем в 
контроле, при этом наиболее сильным ингибитором выступали бактерии Pseudomonas protegens $\mathrm{P} 4-2$.

Проведенное исследование позволило установить, что на этапе адаптации растений Rubus occidentalis Cumberland полученных методом in vitro $\mathbf{\kappa}$ нестерильным условиям, обработка субстрата штаммами бактерий Pseudomonas в разведении 1:5 достоверно увеличивает длину корней и высоту растений. В качестве ингибитора образования междоузлий выступил штамм Pseudomonas putida P82 в разведении 1:5, а ингибитора образования и роста корней Pseudomonas protegens Р4-2 в разведении 1:10.

Исследование выполнено при поддержке гранта Министерства науки и высшего образования РФ в рамках государственного задания по теме «Разработка и внедрение в практику комплексных физико-химических методов оценки состояния растений для решения задач направленного формирования устойчивых культурфитоценозов различного функционального назначения в условиях промышленных и аграрных предприятий» для создания лаборатории физико-химических методов исследования растений.

\section{Список литературы}

1. Акимова С.В., Аладина О.Н., Викулина А.Н. Особенности роста и развития двухлетних ex-vitro растений рода Rubus L. в зависимости от сроков адаптации и подготовки растений к доращиванию // Вестник ландшафтной архитектуры. 2013. № 2. С. 16-22.

2. Райков И.А. Совершенствование клонального микроразмножения межвидовых форм смородины чёрной и малины ремонтантного типа: дисс. ... канд. с.-х. наук: 06.01.05. Брянск, 2011. 132 с.

3. Сковородников Д.Н. Особенности клонального микроразмножения in vitro и ускорение селекции новых ремонтантных форм малины: автореф. дисс. ... канд. с.-х.: 06.01.05, 03.00.12. Брянск, 2004. 20 с.

4. Деменко В.И., Лебедев В.Г., Шестибратов К.А. Адаптация растений, полученных in vitro, к нестерильным условиям // Известия ТСХА. 2010. Вып. 1. C. 73-85.

5. Gresshoff P. Sindicate. Methods employed in planting aut Tissue culture. The horizons of tissue culture propagation // A seminar directed by Dr. R.A. de Fossard for the N.S.W. association of Nurserymen Ltd. At the University of Sydney. 3-4 Desember. Sydney (Australia):University of Sydney, 1977. Pp. 106-108. 
6. Акимова С.В., Аладина О.Н., Киркач В.В., Викулина А.Н., Глинушкин А.П. Эффективность применения модификаций препарата суперстим в малых дозах на этапе индукции ризогенеза растений рода Rubus L. с учетом последействия на этапе адаптации // Достижения науки и техники АПК. 2017. T. 31. № 2. С. 39-44.

7. Акимова С.В., Викулина А.Н., Деменко В.И., Аладина О.Н. Влияние хитозансодержащих препаратов на рост и развитие ex vitro растений рода Rubus L. на этапах адаптации и доращивания // Плодоводство и ягодоводство России. 2016. T. 46. С. 25-28.

8. Викулина A.H. Адаптация растений рода Rubus L., размноженных in vitro, и оценка их последующего развития автореферат дис. ... кандидата сельскохозяйственных наук / Российский государственный аграрный университет-Московская сельскохозяйственная академия имени К.А. Тимирязева. Москва, 201624 с.

9. Preece, J.E. (2002). The most tricky part of micropropagation: establishing plants in greenhouses and fields. Comb. Proc. Intern. Plant Propagators' Soc., vol. 51, pp. 300-303.

10. Муратова С.А. Размножение ягодных культур in vitro / Муратова С.А., Янковская М.Б., Соловых Н.В., Тюленев В.М. //Плодоводство. Ин-т плодоводства Нац. акад. наук Беларуси. Самохваловичи. 2004. Т. 15. С. 232-236.

11. Ван-Ункан Н.Ю. Регенерация растений колонновидных слаборослых генотипов яблони из эксплантов различного происхождения автореф. дисс. ... канд. с.-х.: 06.01.05. Мичуринск-наукоград РФ. 24 с.

12. Chizhik O.V., Filipenya V.L., Reshetnikov V.N. Optimization of Agrobacterial Transformation Methods for Woody Plant Crops // Биологически активные вещества растений - изучение и использование : Материалы Международной научной конференции. Беларусь, Минск, 29-31 мая 2013. Минск: ЦБС НАН Беларуси. - 2013. - С.352-353.

13. Eva Arrebola, Sandra Tienda, Carmen Vida, Antonio de Vicente and Francisco M. Cazorla Fitness Features Involved in the Biocontrol Interaction of Pseudomonas chlororaphis With Host Plants: The Case Study of PcPCL1606 // Front. Microbiol., 10 April 2019| https://doi.org/10.3389/fmicb.2019.00719.

14. Alban Ramette, Michele Frapolli, Marion Fischer-LeSaux, C. Gruffaz, Jean-Marie Meyer, Geneviève Défago, Laurent Sutra, Yvan Moënne-Loccoz Pseudomonas protegens sp. nov., widespread plant-protecting bacteria producing the biocontrol compounds 2,4-diacetylphloroglucinol and pyoluteorin // Systematic and 
Applied Microbiology Volume 34, Issue 3, May 2011, Pages 180-188. https://doi.org/10.1016/j.syapm.2010.10.005.

15. Lázaro Molina, Ana Segura, Estrella Duque, Juan-Luis Ramos Chapter Four - The versatility of Pseudomonas putida in the rhizosphere environment // Advances in Applied Microbiology Volume 110, 2020, Pages 149-180. https://doi.org/10.1016/bs.aambs.2019.12.002. 